\title{
Experimental Verification of Model Simulation Results of Heating Cycles within the Electric Muffle Furnaces
}

\author{
Jiří Lucák \\ Department of Electrical Power Engineering and Environmental Engineering, University of West Bohemia in Pilsen, \\ Czech Republic, e-mail: jlucak@kee.zcu.cz
}

\begin{abstract}
The paper [1] described a mathematical model of the electric muffle furnace. A specific solution of real models has been already solved and presented within this paper. The first one is the muffle heating furnace equipped with a fireproof clay muffle (MODEL I) and thermal insulation of expanded fireproof clay. As the second variant the furnace equipped with a silicon carbide muffle (MODEL II) and with a thermal insulation of fibre ceramic boards of Sibral type is presented. Further the paper presents the results of simulations of the same heating cycles performed using the mathematical model presented in the paper [1] and comparing these results with the progression of the values measured in real furnaces.
\end{abstract}

Experiment and simulation assessment will be carried out as the final step hereof. Equipment parameters are sources from technical documentations of the manufacturers.

Keywords - muffle furnace, thermal process, heating element, furnace lining and mathematical model

\section{MODEL I}

Manufacturer

Elektrim - Poland, year of equipment manufacture: 1963

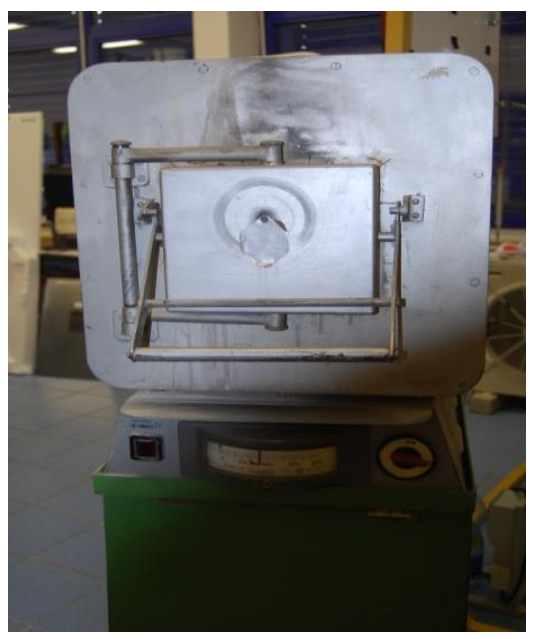

Fig. 1. MODEL I - Fireproof clay muffle furnace.

\section{A. Technical Description}

The muffle furnace is designed for the performance of heating processes; see [1].

Furnace steel construction is made of $2.5 \mathrm{~mm}$ sheet metal. Inside the furnace body is a fireproof clay muffle with a coiled heating element. The muffle inside the muffle is covered with a ceramic material. The heating element is made of the resistance wire KANTHAL A1.

The heating insulation consists of extended fireproof clay furnace blocks. The furnace body is coated with protecting paint.

\section{B. Technical Parameters}

Furnace type

Rated output

PPEM-2/156

Rated voltage

$3.6 \mathrm{~kW}$

$1 \times 220 \mathrm{~V}$

Rated temperature

$1100{ }^{\circ} \mathrm{C}$

Heating element resistance at $20{ }^{\circ} \mathrm{C} \quad 13.2 \Omega$

Heating element material

Diameter of wire

Specific surface load

Kanthal A1

$2.0 \mathrm{~mm}$

$2.0 \mathrm{~W} / \mathrm{cm}^{2}$

C. Furnace Workspace Dimensions

Width

Height

$180 \mathrm{~mm}$

Length

$120 \mathrm{~mm}$

$400 \mathrm{~mm}$

D. Furnace Outer Dimensions

Width

$520 \mathrm{~mm}$

Height

Length

$22 \mathrm{~mm}$

Mass

$150 \mathrm{~kg}$

\section{MODEL II}

\section{A. Technical Description}

The muffle furnace was designed for the purposes of experimental measurement of heating processes using the present-day knowledge within the field, see [1].

Inside the furnace body the $\mathrm{SiC}$ muffle with a coiled heating element of the resistance wire KANTHAL A1 is placed.

Furnace heat insulation is made of fibre materials of high thermal insulation capacity and low energy accumulation. 


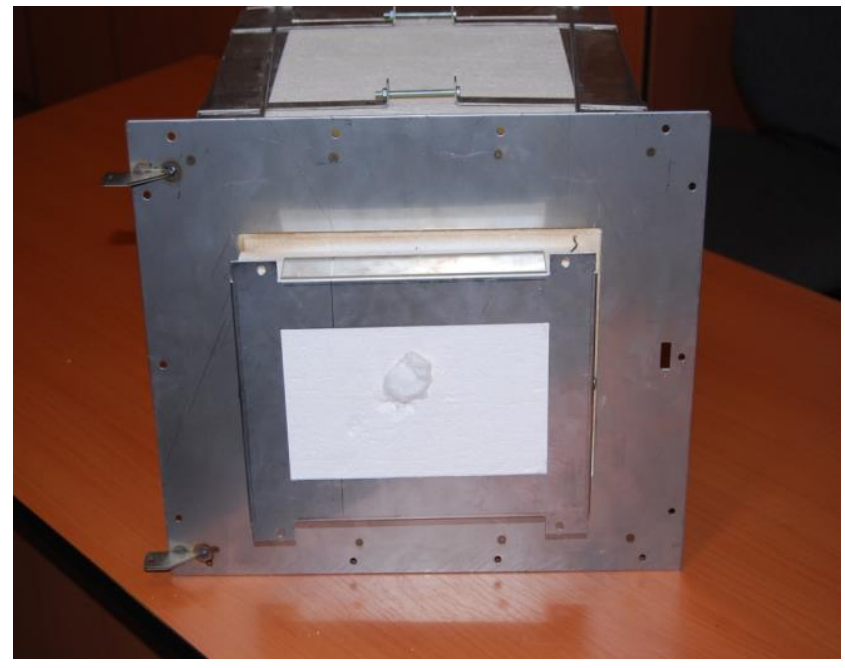

Fig. 2. MODEL II - Fibre materials furnace.

\section{B. Technical Parameters}

Rated output

$2.2 \mathrm{~kW}$

Rated voltage

Rated temperature

$1 \times 230 \mathrm{~V}$

$1100{ }^{\circ} \mathrm{C}$

Heating element resistance at $20{ }^{\circ} \mathrm{C}$

$24.6 \Omega$

Heating element material

Diameter of wire

Specific surface load

\section{Furnace Workspace Dimensions}

Width

Height

170.mm

$95 \mathrm{~mm}$

Length

$320 \mathrm{~mm}$

\section{Furnace Outer Dimensions}

Width

Height

$400 \mathrm{~mm}$

$600 \mathrm{~mm}$

$530 \mathrm{~mm}$

Length

$27 \mathrm{~kg}$

\section{TECHNICAL IMPLEMENTATION OF THE EXPERIMENTS IN THE FURNACES}

The present case means: the furnaces were connected to variable voltage source which consists of a tap-changing transformer of $220 \mathrm{~V}, 180 \mathrm{~V}$ and $155 \mathrm{~V}$ switchable taps. The input power of the heating system is as follows: a step pulse of a constant value of supply voltage for the whole period of the experiment; see Fig. 3.

Resistance of the heating element is temperature dependent; it goes up slightly together with the material temperature, which means that together with the increasing temperature the performance output is falling down.

Manufacturers set the maximum permissible temperature in the furnaces to $1100^{\circ} \mathrm{C}$. Having been aimed not to exceed this temperature during the experiments, it was used the controller with two-position control (ON/OFF) that kept the temperature inside the furnace at this level. The steady-state would reach, at the value of constant output of the used temperature, a higher value than the maximum permissible temperature stated by the manufacturer. However, the maximum permissible temperature could not be exceeded when this kind of regulator was used.

When the experiment was finished, the furnace was switched out and spontaneous cooling was then initiated, starting at the temperature of $1100{ }^{\circ} \mathrm{C}$.

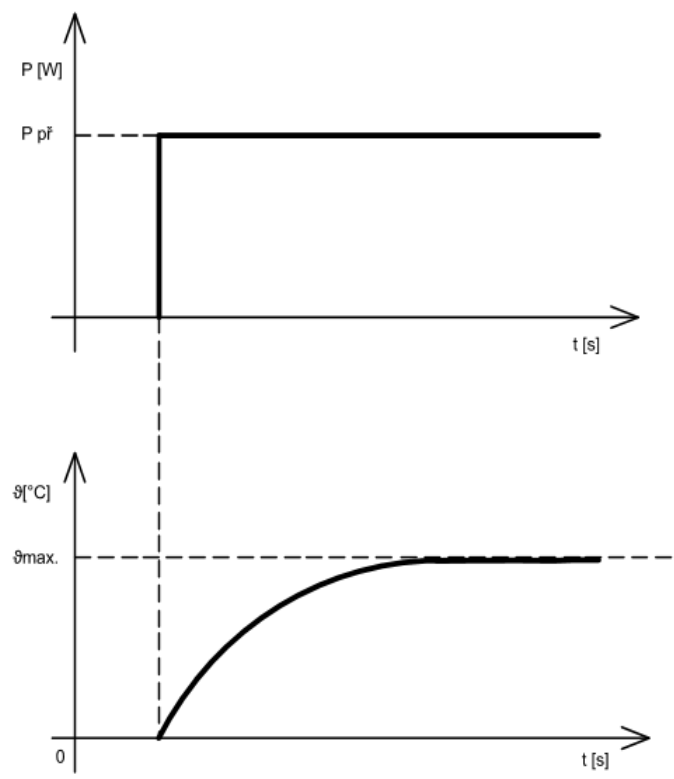

Fig. 3. The performance of the heating system in form of step unit. The estimated run of temperature.

During the experiments it were recorded:

- Thermocouple temperature inside the furnace.

- Temperature of a thermocouple attached to the outer furnace surface.

- Electric voltage at the heating element terminals.

- Electric current flowing through the heating element.

The following charts show the measurement records related to the Model I and Model II.

\section{DESCRIPTION OF THE CHANNELS OF EUROTHERM A 6100 RECORDER}

\begin{tabular}{|c|l|c|l|}
\hline $\begin{array}{c}\text { Channel } \\
1\end{array}$ & Red & $0-1200^{\circ} \mathrm{C}$ & $\begin{array}{l}\text { Temperature } \\
\text { progress in the } \\
\text { furnace workspace }\end{array}$ \\
\hline $\begin{array}{c}\text { Channel } \\
2\end{array}$ & $\begin{array}{l}\text { Light } \\
\text { blue }\end{array}$ & $0-1200^{\circ} \mathrm{C}$ & $\begin{array}{l}\text { Temperature } \\
\text { progress on the } \\
\text { furnace surface }\end{array}$ \\
\hline $\begin{array}{c}\text { Channel } \\
3\end{array}$ & Yellow & $0-250 \mathrm{~V}$ & $\begin{array}{l}\text { Voltage on the } \\
\text { heating element }\end{array}$ \\
\hline $\begin{array}{c}\text { Channel } \\
4\end{array}$ & $\begin{array}{l}\text { Light } \\
\text { green }\end{array}$ & $0-50 \mathrm{~A}$ & $\begin{array}{l}\text { Current flowing } \\
\text { through the heating } \\
\text { element }\end{array}$ \\
\hline $\begin{array}{c}\text { Channel } \\
5\end{array}$ & $\begin{array}{l}\text { Dark } \\
\text { green }\end{array}$ & $0-1$ & $\begin{array}{l}\text { A signal specifying } \\
\text { the area of heating } \\
\text { element connection } \\
\text { to electric energy }\end{array}$ \\
\hline
\end{tabular}




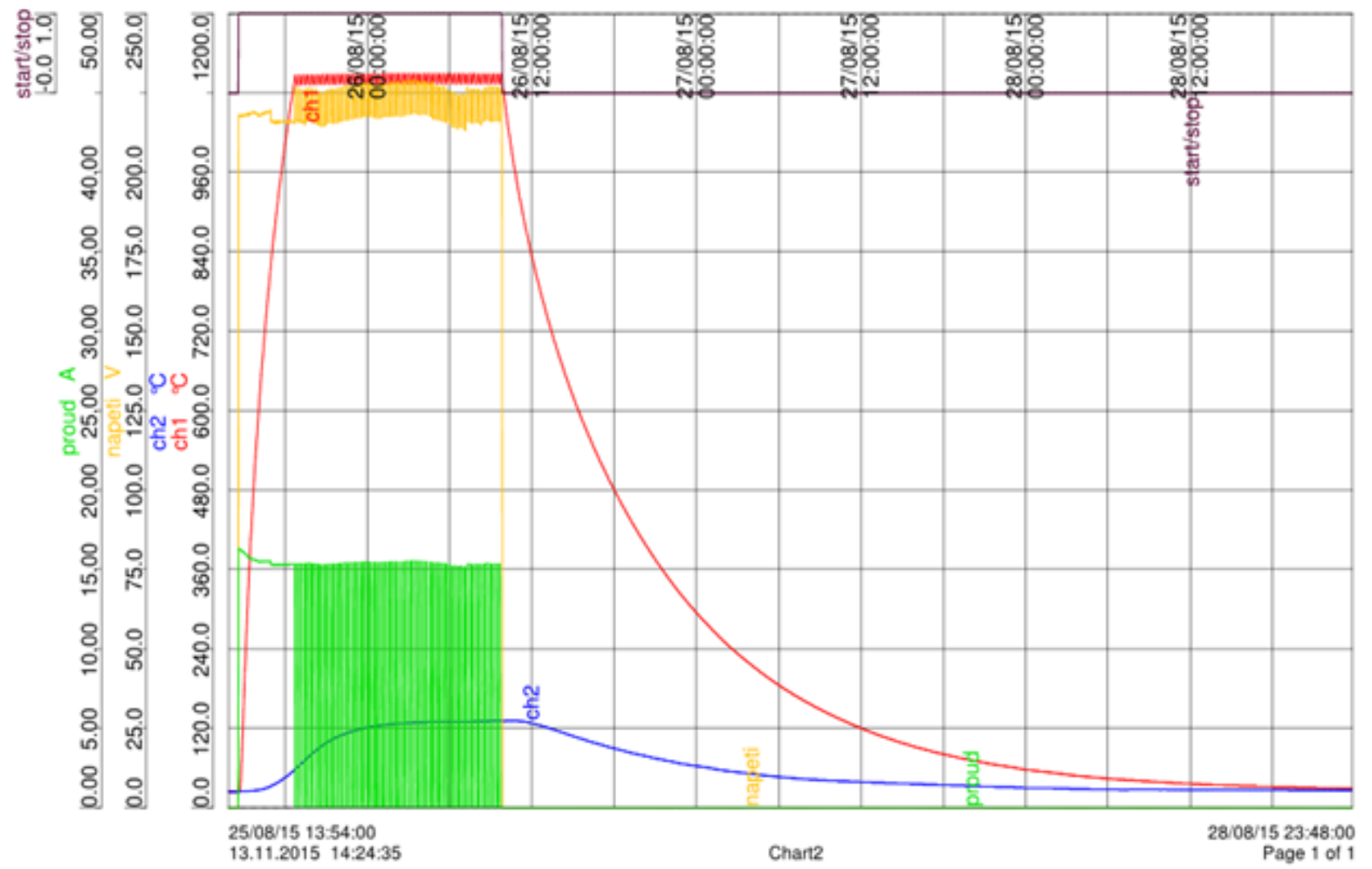

Fig. 4. Records sourced from the EUROTHERM A 6100 recorder - a temperature cycle progression - MODEL I - $220 \mathrm{~V}$ voltage tap.

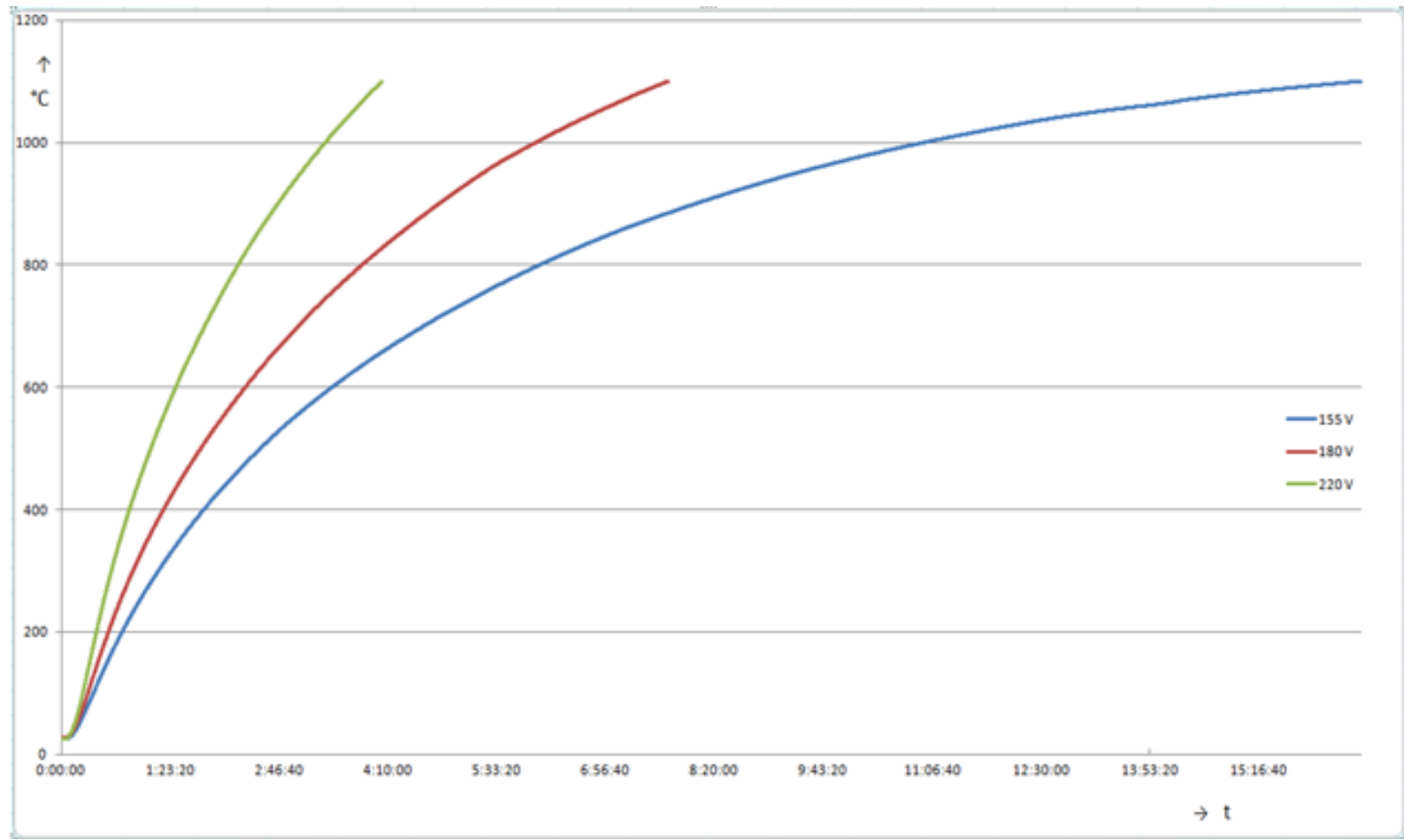

Fig. 5. Temperature progression in the furnace area in MODEL I for the $220 \mathrm{~V}, 180 \mathrm{~V}$ and $155 \mathrm{~V}$ voltage taps. 


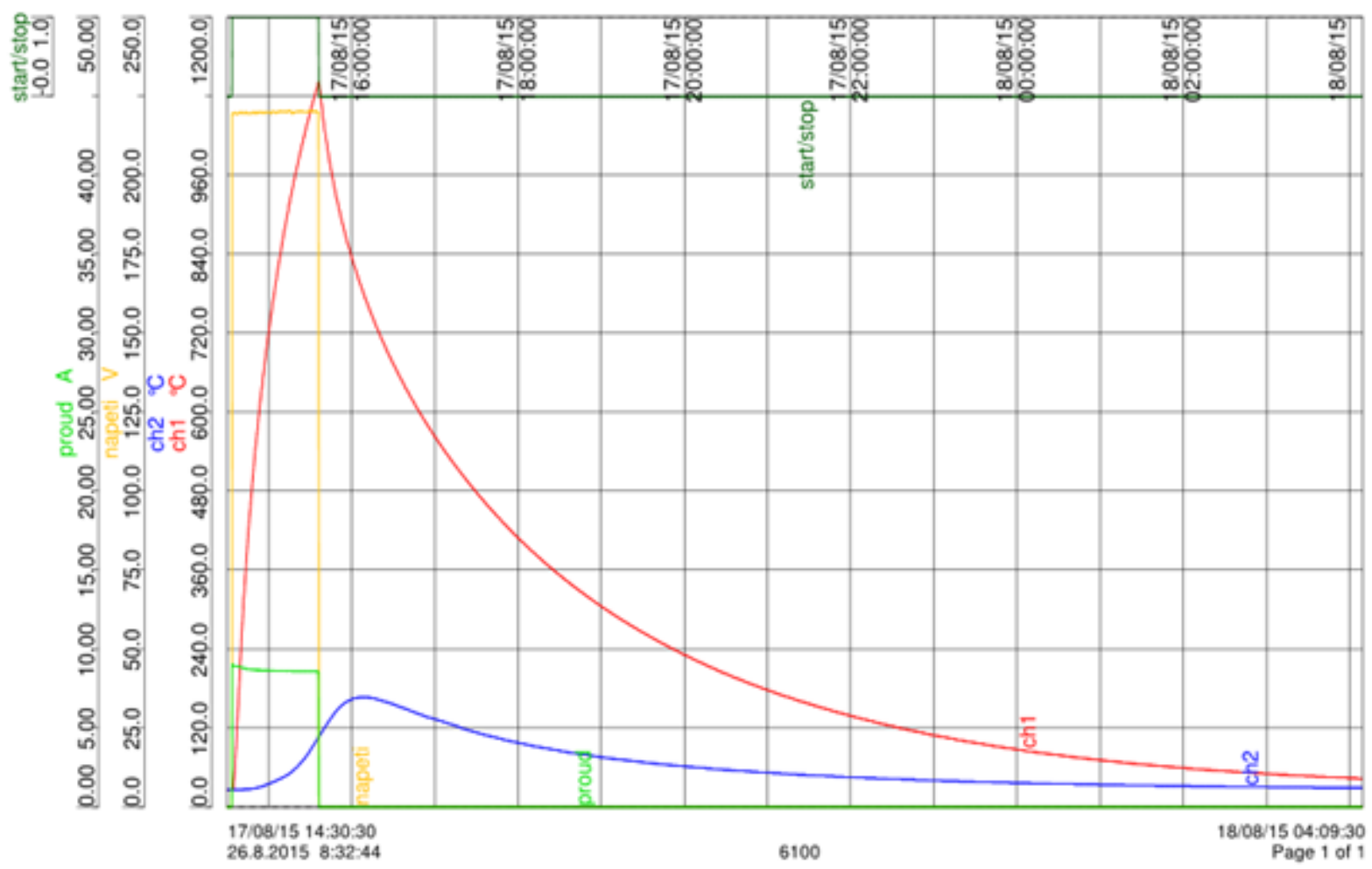

Fig. 6. Records sourced from the EUROTHERM A 6100 recorder - a temperature cycle progression - MODEL II - $220 \mathrm{~V}$ voltage tap.

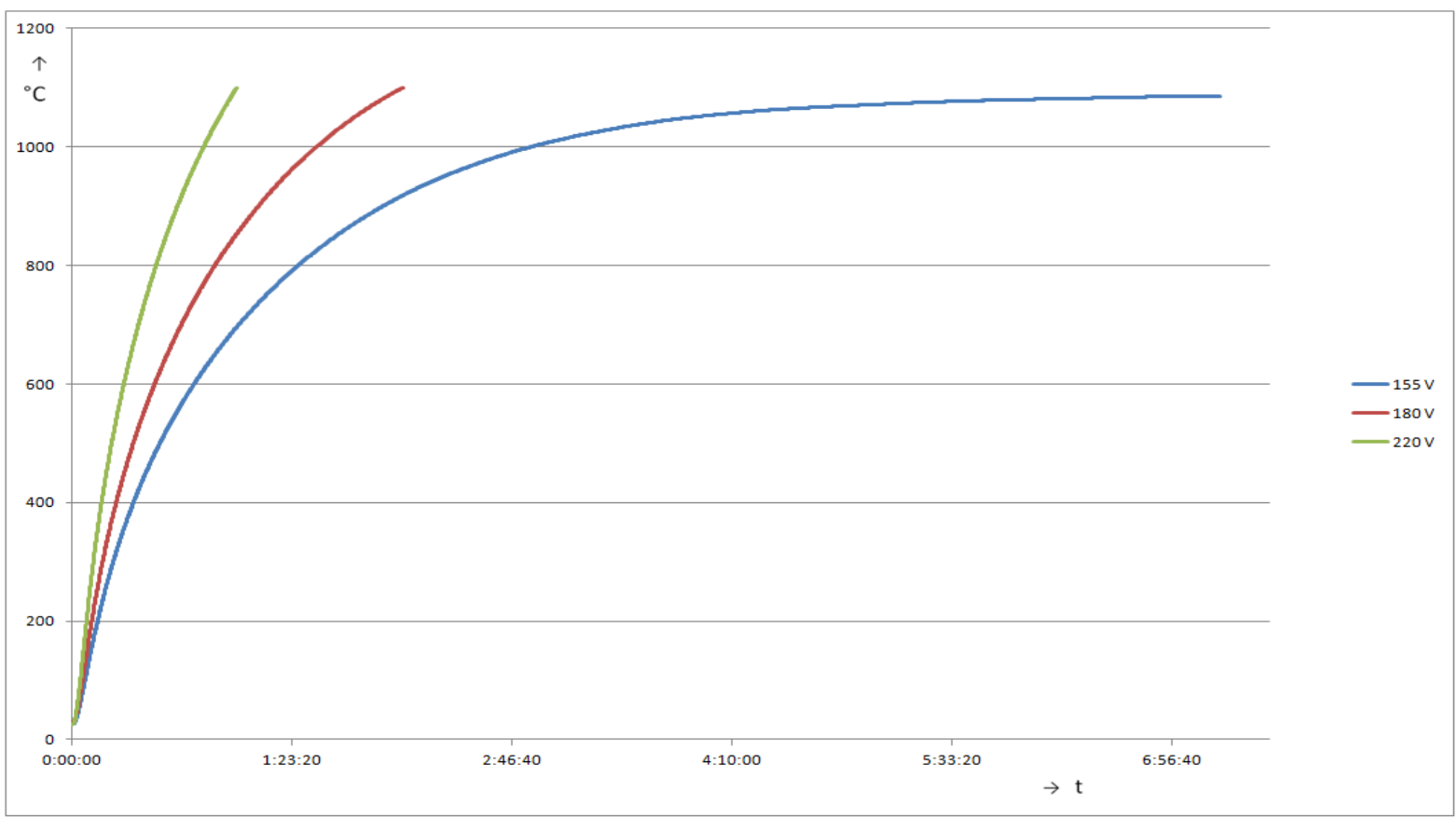

Fig. 7. Temperature progression in the furnace area in MODEL II for the $220 \mathrm{~V}, 180 \mathrm{~V}$ and $155 \mathrm{~V}$ voltage taps. 


\section{HeAting Simulation Using a MATHEMATICAL MODEL OF THE PAPER [1]}

Due to different placing of the heating element in both models, modifications were performed in the differential equation system, as well as in the heat flow relations.

\section{A SYSTEM OF TEMPERATURE DIFFERENTIAL EQUATIONS OF STATE}

Generally: The change of the thermal capacity content is given by the sum of the input heat which flows into the thermal capacity and the heat which flows out the thermal capacity.

a) At Model I

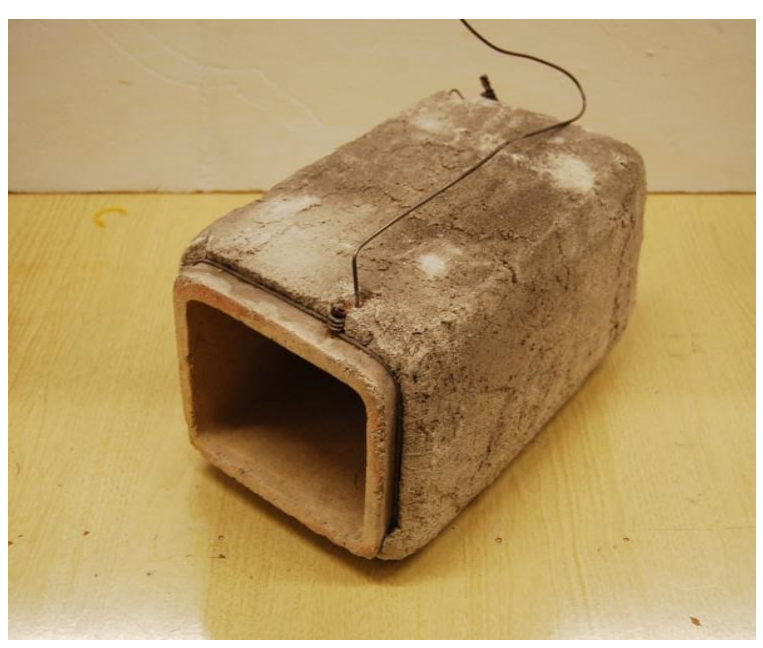

Fig. 8. MODEL I - Fireproof clay muffle.

A furnace made of fireproof clay materials consists of a heating coil which is poured with and embedded in the clay material which covers the muffle. In this case, the mass of the coil and the clay material is included in the M1 and a transfer carried out from it into the muffle and the surrounding insulation is understood as conductive transfer.

\section{b) At Model II}

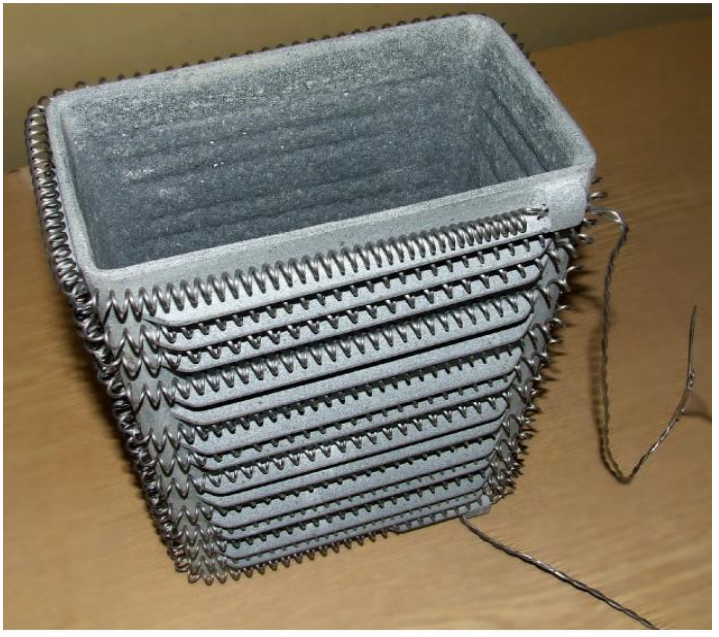

Fig. 9. MODEL II - The SiC muffle.
The Sibral furnace $+\mathrm{SiC}$, where the heating coil is placed unfixed in the space between the muffle and the Sibral boards the heat transfer is understood as the thermal radiation from a coil towards the muffle $q_{1,2}$, from a coil towards the Sibral $q_{1,4}$ and from the muffle towards the Sibral $q_{2,4}$. The convection is not considered.

For the reasons of clarity it is to show the modified relations within the Model I and II.

\section{Heating coil:}

$$
M_{1} c_{1} \frac{\mathrm{d} t_{1}}{\mathrm{~d} \tau}=q_{\mathrm{el}}-q_{1,2}-q_{1,4}
$$

Model I - the fireproof clay muffle:

$$
M_{2} c_{2} \frac{\mathrm{d} t_{2}}{\mathrm{~d} \tau}=q_{1,2}-q_{2,3},
$$

Model II - the SiC muffle:

$$
\begin{gathered}
M_{2} c_{2} \frac{\mathrm{d} t_{2}}{\mathrm{~d} \tau}=q_{1,2}-q_{2,3}-q_{2,4}, \\
M_{3} c_{3} \frac{\mathrm{d} t_{3}}{\mathrm{~d} \tau}=q_{2,3}-q_{3,8 S}-q_{3,13 K}-q_{3,14 S},
\end{gathered}
$$

Side walls + ceiling + hearth lining of the furnace: Model I:

$$
M_{4} c_{4} \frac{\mathrm{d} t_{4}}{\mathrm{~d} \tau}=q_{1,4}-q_{4,5},
$$

Model II:

$$
\begin{gathered}
M_{4} c_{4} \frac{\mathrm{d} t_{4}}{\mathrm{~d} \tau}=q_{1,4}+q_{2,4}-q_{4,5}, \\
M_{5} c_{5} \frac{\mathrm{d} t_{5}}{\mathrm{~d} \tau}=q_{4,5}-q_{5,6}, \\
M_{6} c_{6} \frac{\mathrm{d} t_{6}}{\mathrm{~d} \tau}=q_{5,6}-q_{6,7}, \\
M_{7} c_{7} \frac{\mathrm{d} t_{7}}{\mathrm{~d} \tau}=q_{6,7}-q_{7, \mathrm{ok} \mathrm{k}}-q_{7, \mathrm{oks}} .
\end{gathered}
$$

The door + back walls lining:

$$
\begin{gathered}
M_{8} c_{8} \frac{\mathrm{d} t_{8}}{\mathrm{~d} \tau}=q_{3,8 \mathrm{~s}}-q_{8,9}-q_{8,13 \mathrm{k}}-q_{8,14 \mathrm{~s}} \\
M_{9} c_{9} \frac{\mathrm{d} t_{9}}{\mathrm{~d} \tau}=q_{8,9}-q_{9,10} \\
M_{10} c_{10} \frac{\mathrm{d} t_{10}}{\mathrm{~d} \tau}=q_{9,10}-q_{10,11} \\
M_{11} c_{11} \frac{\mathrm{d} t_{11}}{\mathrm{~d} \tau}=q_{10,11}-q_{11,12} \\
M_{12} c_{12} \frac{\mathrm{d} t_{12}}{\mathrm{~d} \tau}=q_{11,12}-q_{12, \mathrm{ok} \mathrm{k}}-q_{12, \mathrm{oks}}
\end{gathered}
$$

\section{Gas in the furnace:}

$$
M_{13} c_{13} \frac{\mathrm{d} t_{13}}{\mathrm{~d} \tau}=q_{3,13 \mathrm{k}}+q_{8,13 \mathrm{k}}-q_{13,14 \mathrm{k}} .
$$




\section{Thermometer:}

$$
M_{14} c_{14} \frac{\mathrm{d} t_{14}}{\mathrm{~d} \tau}=q_{13,14 \mathrm{k}}+q_{3,14 \mathrm{~s}}+q_{8,14 \mathrm{~s}}
$$

\section{RELATIONS FOR HEAT FLOWS}

The input power flowing into the furnace is affected by the change of rated resistivity of the heating element according to the temperature $\mathrm{t} 1$ and may be regulated according to the thermocouple temperature $t_{14}$, eventually according to the time $\tau$.

$$
q_{\mathrm{el}}=q_{\mathrm{el}}\left(\tau, t_{1}, t_{14}\right)
$$

Model I - the flow $q_{2,4}$ is not in the fireproof clay furnace version:

$$
\begin{aligned}
& q_{1,2}=S_{1,2}\left(t_{1}-t_{2}\right) /\left(s_{1} / 2 \lambda_{1}+s_{2} / 2 \lambda_{2}\right) \\
& q_{1,4}=S_{1,4}\left(t_{1}-t_{4}\right) /\left(s_{1} / 2 \lambda_{1}+s_{4} / 2 \lambda_{4}\right)
\end{aligned}
$$

Model II - from the Sibral and SiC furnace version:

$$
\begin{aligned}
& q_{1,2}=\varepsilon_{\check{c}} \varepsilon_{1,2}\left(\left(t_{1}+273\right)^{4}-\left(t_{2}+273\right)^{4}\right) S_{1,2} \varphi_{1,2} \\
& q_{1,4}=\varepsilon_{\check{c}} \varepsilon_{1,4}\left(\left(t_{1}+273\right)^{4}-\left(t_{4}+273\right)^{4}\right) S_{1,4} \varphi_{1,4} \\
& q_{2,4}=\varepsilon_{\check{c}} \varepsilon_{2,4}\left(\left(t_{2}+273\right)^{4}-\left(t_{4}+273\right)^{4}\right) S_{2,4} \varphi_{2,4}
\end{aligned}
$$

Next, for both versions it is applied the following:

$$
\begin{gathered}
q_{2,3}=S_{2,3}\left(t_{2}-t_{3}\right) /\left(s_{2} / 2 \lambda_{2}+s_{3} / 2 \lambda_{3}\right) \\
q_{3,13 \mathrm{k}}=S_{3,13}\left(t_{3}-t_{13}\right) \alpha_{\mathrm{k} 3} \\
q_{3,8 \mathrm{~s}}=\varepsilon_{\check{\mathrm{c}}} \varepsilon_{3,8}\left(\left(t_{3}+273\right)^{4}-\left(t_{8}+273\right)^{4}\right) S_{3,8} \varphi_{3,8} \\
q_{3,14 \mathrm{~s}}=\varepsilon_{\check{\mathrm{c}}} \varepsilon_{3,14}\left(\left(t_{3}+273\right)^{4}-\left(t_{14}+273\right)^{4}\right) S_{3,14} \varphi_{3,14} \\
q_{1,4}=S_{1,4}\left(t_{1}-t_{4}\right) /\left(s_{4} / 2 \lambda_{4}\right) \\
q_{4,5}=S_{4,5}\left(t_{4}-t_{5}\right) /\left(s_{4} / 2 \lambda_{4}+s_{5} / 2 \lambda_{5}\right) \\
q_{5,6}=S_{5,6}\left(t_{5}-t_{6}\right) /\left(s_{5} / 2 \lambda_{5}+s_{6} / 2 \lambda_{6}\right) \\
q_{6,7}=S_{6,7}\left(t_{6}-t_{7}\right) /\left(s_{6} / 2 \lambda_{6}+s_{7} / 2 \lambda_{7}\right) \\
q_{7, \mathrm{ok}}=S_{7, \mathrm{ok}}\left(t_{7}-t_{\mathrm{ok}}\right) \alpha_{\mathrm{k} 7} \\
q_{7, \mathrm{ok} \mathrm{s}}=\varepsilon_{\mathrm{c}} \varepsilon_{7, \mathrm{ok}}\left(\left(t_{7}+273\right)^{4}-\left(t_{\mathrm{ok}}+273\right)^{4}\right) S_{7, \mathrm{ok}} \varphi_{7, \mathrm{ok}} \\
q_{8,9}=S_{8,9}\left(t_{8}-t_{9}\right) /\left(s_{8} / 2 \lambda_{8}+s_{9} / 2 \lambda_{9}\right) \\
q_{8,14 \mathrm{~s}}=\varepsilon_{\check{\mathrm{c}}} \varepsilon_{8,14}\left(\left(t_{8}+273\right)^{4}-\left(t_{14}+273\right)^{4}\right) S_{8,14} \varphi_{8,14} \\
q_{9,10}=S_{9,10}\left(t_{9}-t_{10}\right) /\left(s_{9} / 2 \lambda_{9}+s_{10} / 2 \lambda_{10}\right) \\
=S_{10,11}\left(t_{10}-t_{11}\right) /\left(s_{10} / 2 \lambda_{10}+s_{11} / 2 \lambda_{11}\right) \\
q_{12, \mathrm{ok}}=S_{11,12}\left(t_{11}-t_{12}\right) /\left(s_{11} / 2 \lambda_{11}+s_{12} / 2 \lambda_{12}\right) \\
\left.q_{8}-t_{13}\right) \alpha_{\mathrm{k} 8}\left(t_{12}-t_{\mathrm{ok}}\right) \alpha_{\mathrm{k} 12} \\
q_{10,13}
\end{gathered}
$$

$$
\begin{gathered}
q_{12, \mathrm{oks}}=\varepsilon_{\check{\mathrm{c}}} \varepsilon_{12, \mathrm{ok}}\left(\left(t_{12}+273\right)^{4}-\left(t_{\mathrm{ok}}+273\right)^{4}\right) S_{12, \mathrm{ok}} \varphi_{12, \mathrm{ok}} \\
q_{13,14 \mathrm{k}}=S_{13,14}\left(t_{13}-t_{14}\right) \alpha_{\mathrm{k} 14} \\
q_{\mathrm{ok}}=q_{7, \mathrm{ok} \mathrm{k}}+q_{7, \mathrm{oks}}+q_{12, \mathrm{ok} \mathrm{k}}+q_{12, \mathrm{oks}}
\end{gathered}
$$

The time course of the thermal process in a real furnace is in the mathematical model simulated using the movement trajectory in a 15 dimension space-time coordinates of which are: $\left(\tau, t_{1}, t_{2}, t_{3}, t_{4}, t_{5}, t_{6}, t_{7}, t_{8}, t_{9}, t_{10}, t_{11}, t_{12}, t_{13}, t_{14}\right)$.

\section{PHYSICAL PARAMETERS OF MATERIALS}

\section{Heating coil - Kanthal A1}

Model I - Kanthal + fireproof clay material

Specific mass $\rho\left(\mathrm{kg} / \mathrm{m}^{3}\right): \quad 1071$

Specific heat $c(\mathrm{~J} / \mathrm{kgK}): \quad 934+0.671 t$

Heat conductivity $\lambda(\mathrm{W} / \mathrm{mK}): \quad 0.417+8.69 \cdot 10^{-5} t$

Diameter of heating coil: $0.014 \mathrm{~m}$, diameter of wire: $2.0 \mathrm{~mm}$, length of wire: $30.3 \mathrm{~m}$.

\section{Model II}

Mass $M(\mathrm{~kg}): \quad 0.281$

Specific heat $c(\mathrm{~J} / \mathrm{kgK}): \quad 460$

Emissivity $\varepsilon(1)$ : $\quad 0.7$

Diameter of heating coil: $0.010 \mathrm{~m}$, diameter of wire: $1.4 \mathrm{~mm}$, length of wire: $25.75 \mathrm{~m}$.

\section{Muffle}

Model I - dense fireproof clay SII

Specific mass $\rho\left(\mathrm{kg} / \mathrm{m}^{3}\right)$ :

Specific heat $c(\mathrm{~J} / \mathrm{kgK})$ :

1900

Heat conductivity $\lambda(\mathrm{W} / \mathrm{mK})$ :

Emissivity $\varepsilon(1)$ :

$934+0.671 t$

$1.12+1.75 \cdot 10^{-4} t$

$0.85-1 \cdot 10^{-4} t$

Model II - Silicon carbide SiC

Specific mass $\rho\left(\mathrm{kg} / \mathrm{m}^{3}\right)$ :

3100

Specific heat $c(\mathrm{~J} / \mathrm{kgK})$ :

$$
642+1.648 t-0.0015 t^{2}+0.0000005 t^{3}
$$

Heat conductivity $\lambda(\mathrm{W} / \mathrm{mK}): \quad 60$

Emissivity $\varepsilon$ (1):

\section{Furnace lining}

Model I - Foamed clay

Specific mass $\rho\left(\mathrm{kg} / \mathrm{m}^{3}\right)$ :

Specific heat $c(\mathrm{~J} / \mathrm{kgK})$ :

732

Heat conductivity $\lambda(\mathrm{W} / \mathrm{mK})$ :

Emissivity $\varepsilon(1)$ :

$934+0.671$

Steel sheathing: $2.5 \mathrm{~mm}$, emissivity of the Al paint: 0.5 .

Model II - Sibral boards (Ceraboard)

Specific mass $\rho\left(\mathrm{kg} / \mathrm{m}^{3}\right)$ :

Specific heat $c(\mathrm{~J} / \mathrm{kgK})$ :

$310 \cdot 1.5$

Heat conductivity $\lambda(\mathrm{W} / \mathrm{mK})$ :

Emissivity $\varepsilon(1)$

$$
0.078-1.74 \cdot 10^{-5} t+1.65 \cdot 10^{-7} t^{2}
$$
0.56

\section{Gas inside the furnace - Nitrogen}

Specific mass $\rho\left(\mathrm{kg} / \mathrm{m}^{3}\right)$ : $1.25 \cdot 273 /\left(t_{13}+273\right)$

Specific heat $c(\mathrm{~J} / \mathrm{kgK})$ : 1043

\section{Thermometer - sheathed thermocouple NiCr-Ni}

Specific mass $\rho\left(\mathrm{kg} / \mathrm{m}^{3}\right)$ : 4000

Specific heat $c(\mathrm{~J} / \mathrm{kgK})$ :

Emissivity $\varepsilon$ (1):

$0.65+1.22 \cdot 10^{-4} t$ 


\section{GEOMETRY OF MODEL}

Model I

\section{Furnace outer dimensions}

$\begin{array}{ll}\text { Width }(\mathrm{m}): & 0.520 \\ \text { Height }(\mathrm{m}): & 0.520 \\ \text { Depth }(\mathrm{m}): & 0.600\end{array}$

\section{Muffle outer dimensions}

$\begin{array}{ll}\text { Width }(\mathrm{m}): & 0.210 \\ \text { Height }(\mathrm{m}): & 0.160 \\ \text { Depth }(\mathrm{m}): & 0.415\end{array}$

\section{Muffle inner dimensions}

$\begin{array}{ll}\text { Width (m): } & 0.180 \\ \text { Height (m): } & 0.130 \\ \text { Depth (m): } & 0.400\end{array}$

Thickness of the insulation lining of the side walls (m): 0.135

Thickness of the insulation lining of the ceiling and furnace hearth $(\mathrm{m})$ : 0.160

Thickness of the insulation lining of the door and back wall (m): $\quad 0.140$

Thickness of the furnace steel sheathing $(\mathrm{m})$ :

0.0025

\section{Sheathed thermocouple}

Diameter (m): $\quad 0.002$

The length sticking out into the furnace $(\mathrm{m}): 0.050$

\section{Model II}

\section{Furnace outer dimensions}

$\begin{array}{ll}\text { Width }(\mathrm{m}): & 0.325 \\ \text { Height }(\mathrm{m}): & 0.245 \\ \text { Depth }(\mathrm{m}): & 0.320\end{array}$

\section{Muffle outer dimensions}

$\begin{array}{ll}\text { Width }(\mathrm{m}): & 0.185 \\ \text { Height }(\mathrm{m}): & 0.105 \\ \text { Depth }(\mathrm{m}): & 0.290\end{array}$

\section{Muffle inner dimensions}

$\begin{array}{ll}\text { Width }(\mathrm{m}): & 0,175 \\ \text { Height }(\mathrm{m}): & 0.095 \\ \text { Depth }(\mathrm{m}): & 0.280\end{array}$

Thickness of the insulation lining of the side walls, ceiling and furnace hearth $(\mathrm{m}): \quad 0.060$

Thickness of the insulation lining of the door and back wall (m): 0.040

\section{Sheathed thermocouple}

Diameter (m) 0.002

The length sticking out into the furnace $(\mathrm{m}): 0.050$

\section{DETERMinAtion OF THE $\alpha, \varepsilon, \varphi$ VALUES}

\section{Coefficients of convective heat passage $\alpha_{\mathrm{k}, \mathrm{i}}$}

Inside the furnace, as well as on its outer surface, there is no forced gas flow, so in both cases we can count with natural convection.
To determine the coefficients of convection passage the criterion equations of similarity analysis are used.

Considering the fact that together with the growing temperature the convection ratio against the radiation is rapidly falling down, any detailed calculation will not be presented for the convection case and similar cases values, verified by practice, will be used.

The natural convection on the furnace outer surface may be calculated as follows: $\alpha_{\mathrm{k}}=4\left(\mathrm{~W} / \mathrm{m}^{2} \mathrm{~K}\right)$. On the furnace inner surface: $\alpha_{\mathrm{k}}=8\left(\mathrm{~W} / \mathrm{m}^{2} \mathrm{~K}\right)$.

\section{Relative emissivity $\varepsilon_{i, j}$}

Within a closed set of two isothermal areas of the relative emissivity $\varepsilon_{1}$ and $\varepsilon_{2}$ is valid:

$$
\varepsilon_{1,2}=1 /\left(1 / \varepsilon_{1}+1 / \varepsilon_{2}-1\right)
$$

\section{Angular coefficients of the exposure to radiation $\varphi_{1, \mathrm{j}}$}

For a closed set of two isothermal areas $F_{1}$ and $F_{2}$ it is valid:

$$
\begin{gathered}
\varphi_{1,2}=1 \\
\varphi_{1,2}=\frac{F_{1}}{F_{2}} \\
F_{1,2}=F_{1}
\end{gathered}
$$
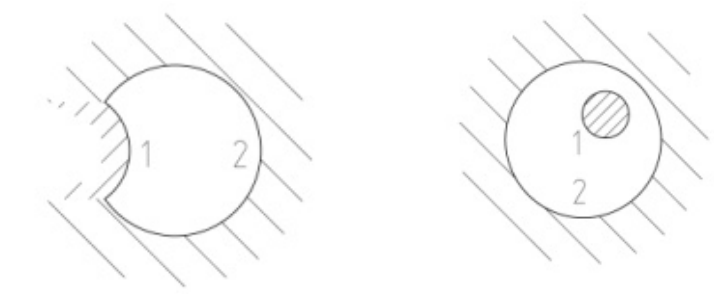
Fig. 10.a A closed set of curved
concave and non-concave

Fig. 10.b A body of nonconcave surface is inside a body of a concave surface.

These relations will be used to determine

$$
\varphi_{3,8}=S_{8} / S_{3}, S_{3,8}=S_{8}
$$

Temperature sensor is from all its sides surrounded with radiating surfaces $S_{3}$ and $S_{8}$.

For angular coefficients $\varphi_{3,14}$ and $\varphi_{8,14}$ :

$$
\varphi_{3,14}+\varphi_{8,14}=1
$$

Using the mathematical models of fireproof clay and Sibral furnaces the simulations imitating the measured heats, heat persistence and cooling of real furnaces were performed.

\section{GRAPHICAL REPRESENTATION OF SIMULATION RESULTS}

The dashed line is used for the temperature courses measured at the furnace, and the dotted line is used to mark the corresponding course which was calculated. 


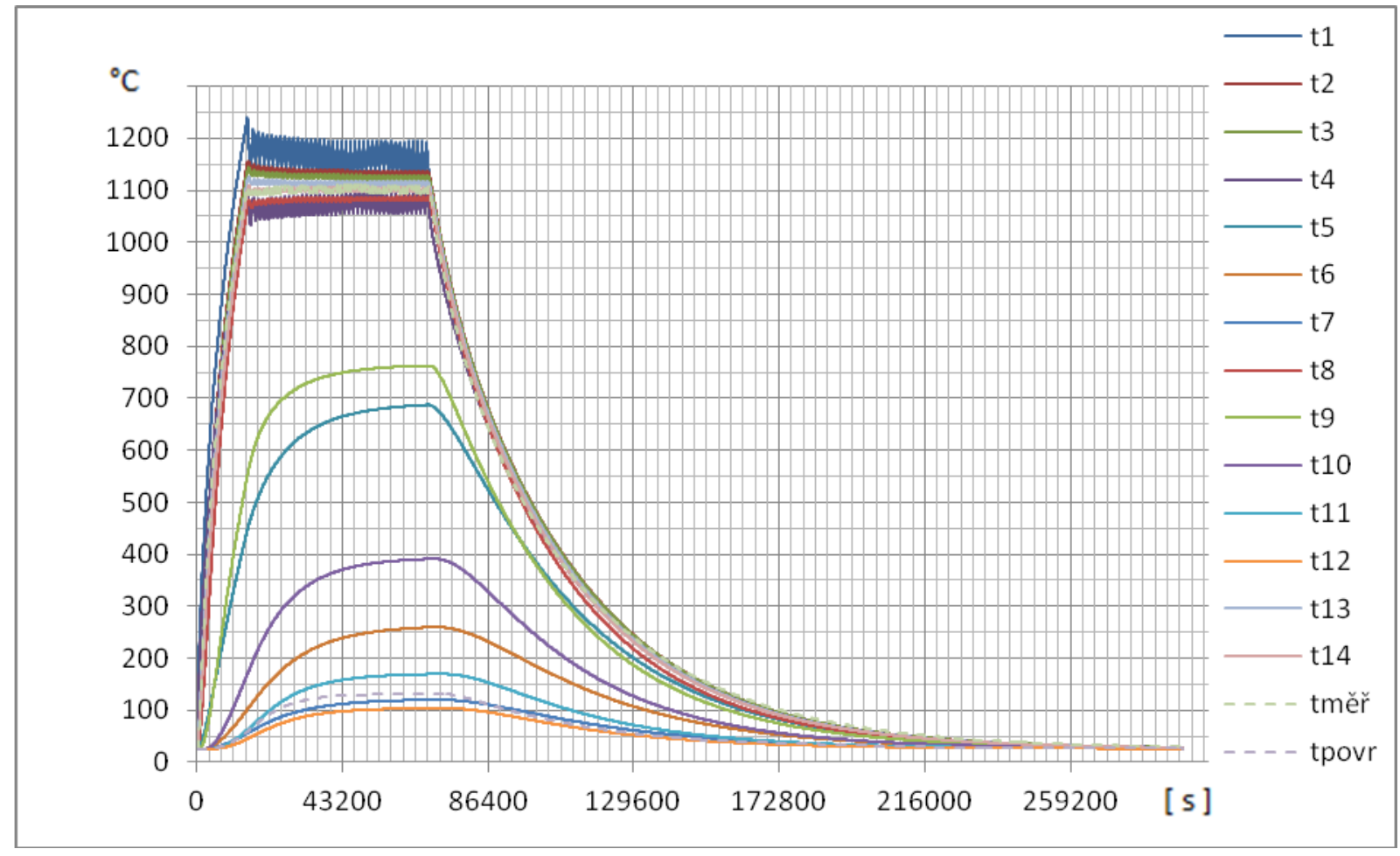

Fig. 11. MODEL I - Temperatures - Tap voltage $220 \mathrm{~V}$.

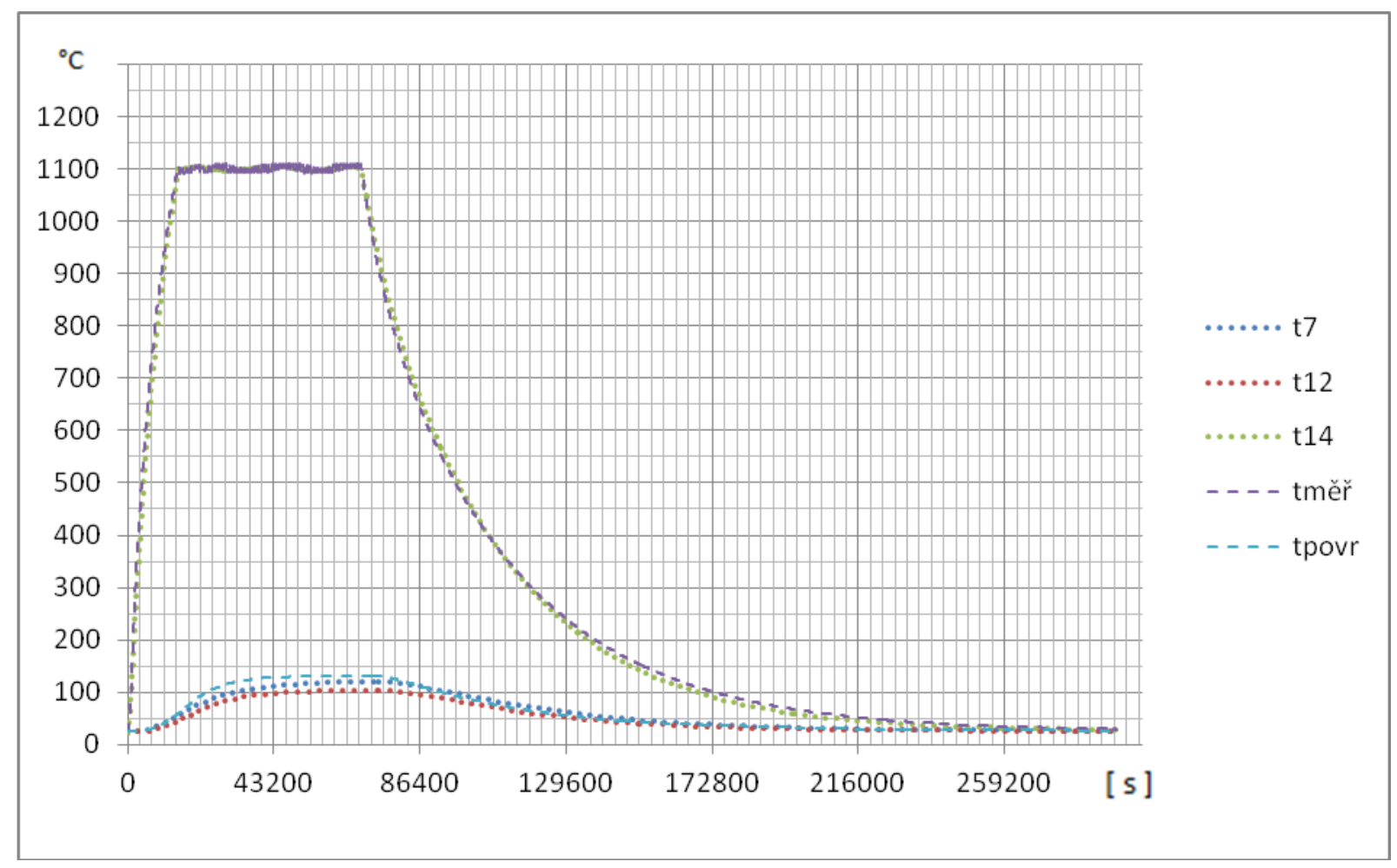

Fig. 12. MODEL I - Selected temperatures - Tap voltage $220 \mathrm{~V}$. 


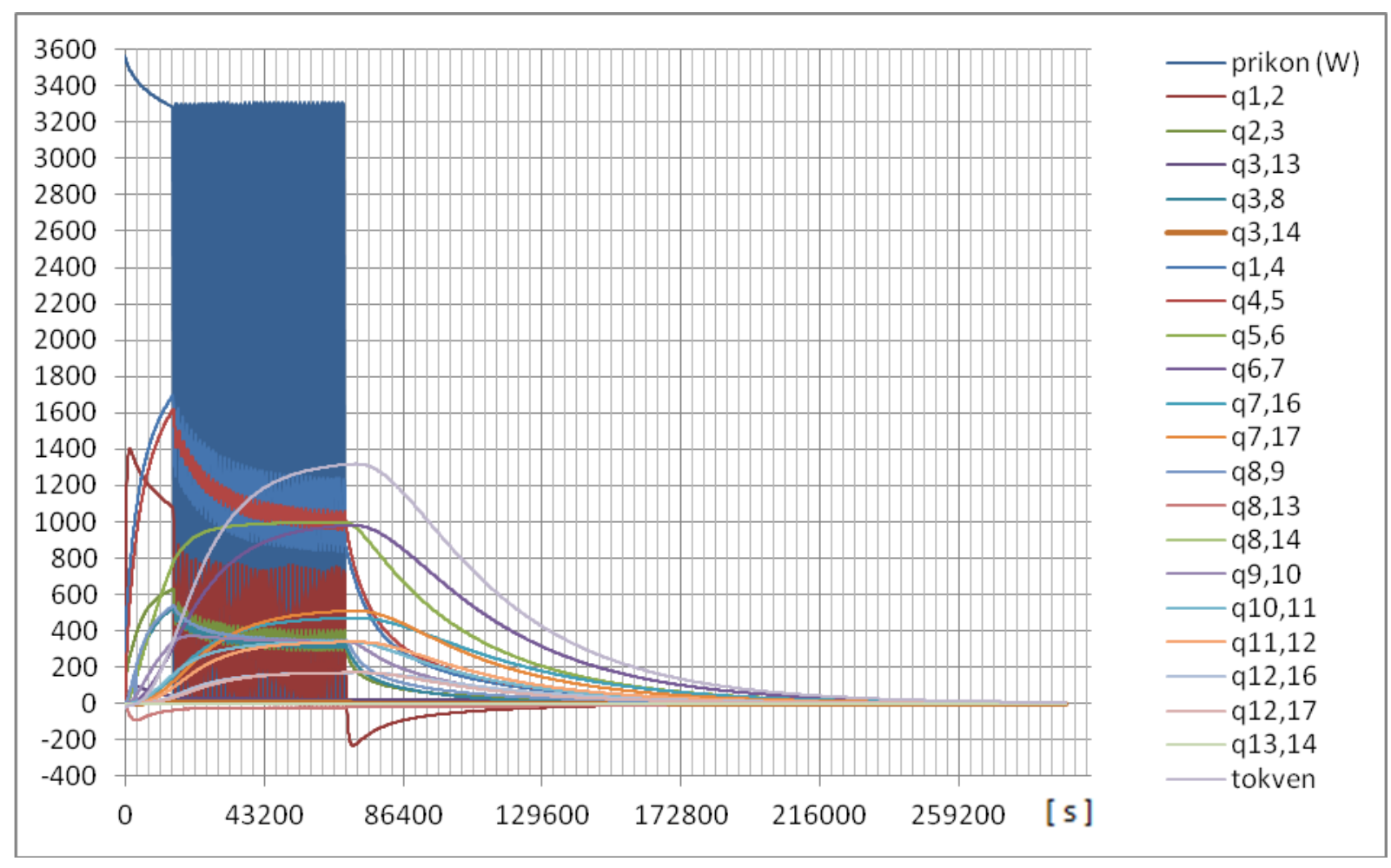

Fig. 13. MODEL I - Heat flows - Tap voltage $220 \mathrm{~V}$.

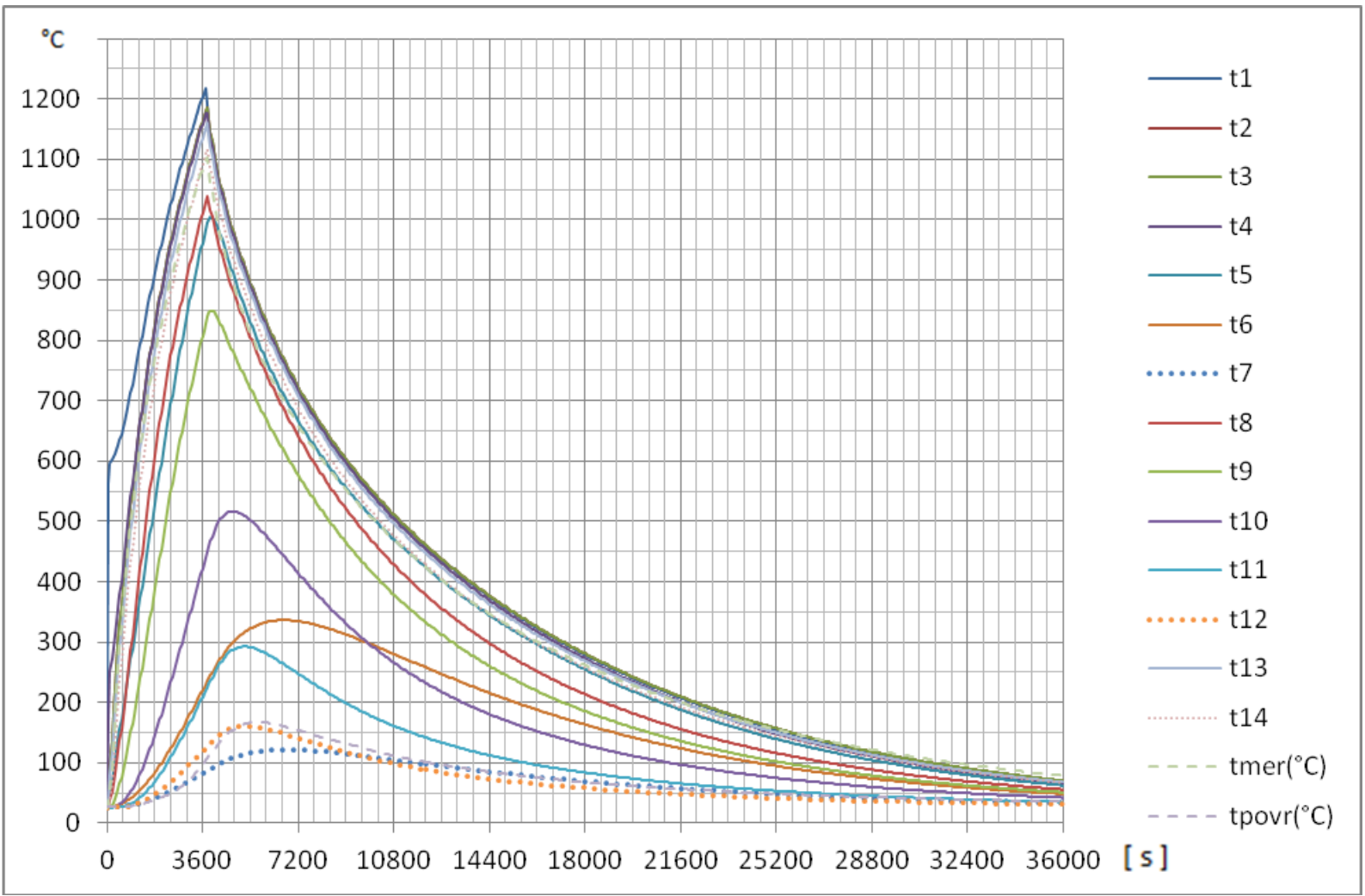

Fig. 14. MODEL II - Temperatures - Tap voltage $220 \mathrm{~V}$. 


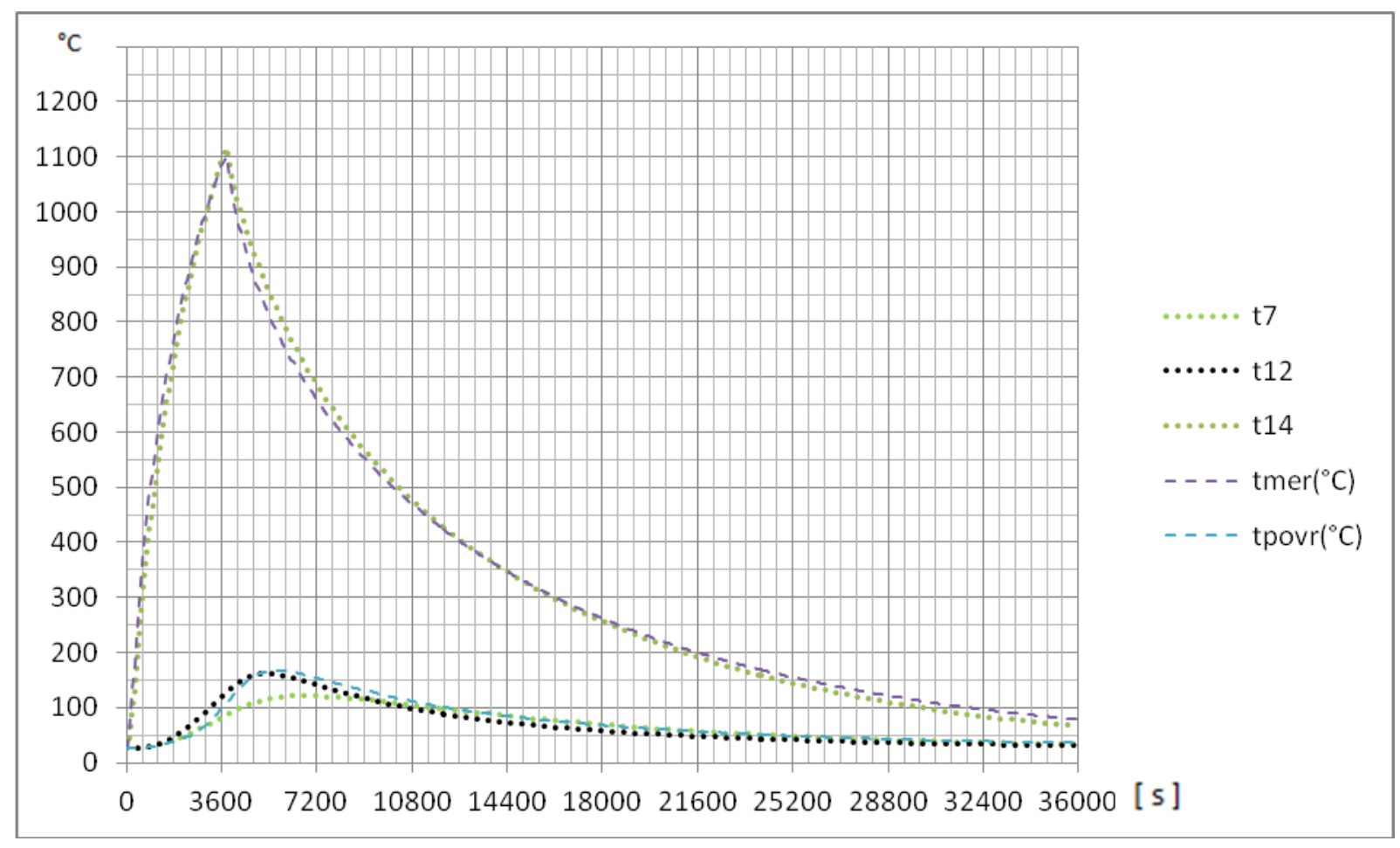

Fig. 15. MODEL II - Selected temperatures - Tap voltage $220 \mathrm{~V}$.

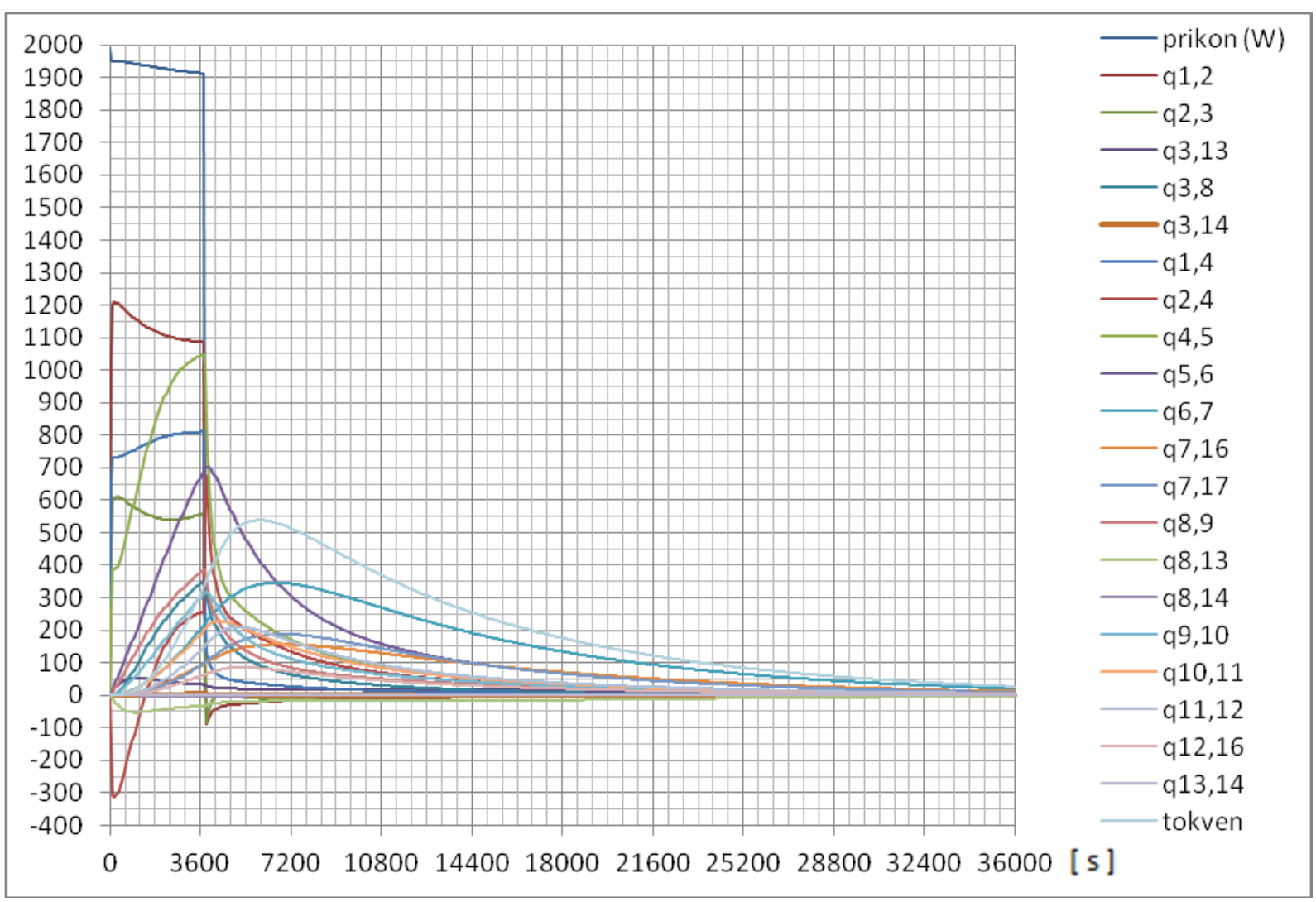

Fig. 16. MODEL II - Heat flows - Tap voltage $220 \mathrm{~V}$. 


\section{CONCLUSION}

Comparing the courses of temperatures measured in real furnaces with the courses of the calculated simulations using the mathematical models shows the results of very good matching.

Thus, it can be concluded that the developed mathematical model of a heating and cooling within the electric muffle furnace imitates at a good level the processes which are being performed in real furnaces.

Generally, it is valid that simulations in computer models of dynamic systems are typical for a number of advantages against the experiments performed on real equipment and devices. Using them we are allowed to test the behaviour of such equipment that are being designed and have not been existed yet. Also, in this way, we have the possibility to simulate the states or processes that would be in case of real equipment understood as risky ones or high-priced.

However, the mathematical models bear also significant risks, their behaviour differs significantly from the real situation, if, in particular, in case of their development were used improper simplifications or if wrong ideas of their developers were applied.

\section{REFERENCES}

[1] J. Lucák, "A Mathematical Model of Thermal Processes in the Empty Electric Muffle Furnace," Transactions on Electrical Engineering, vol. 5, pp. 14-20, March 2016. http://dx.doi.org/10.14311/TEE.2016.1.014 